\title{
Intramedullary Abscess of the Spinal Cord in Children: A Case Report and Review of the Literature
}

\author{
Hisham Ben Khayal ${ }^{1}$, Abulsalam Abugrara ${ }^{2}$ and Muffaq lashhab ${ }^{3 *}$ \\ ${ }^{1}$ Associate Professor of Neurosurgery, Tripoli University, Libya \\ ${ }^{2}$ Professor of Radiology, Triploi University, Libya \\ ${ }^{3}$ Neurosurgeon, Tripoli University, Libya
}

Submission: March 11, 2017; Published: June 05, 2017

*Corresponding author: Muffaq lashhab, Neurosurgeon, Tripoli University, Libya, Email: muaffaq.mkls@gmail.com

\begin{abstract}
Intramedullary spinal cord abscess (ISCA) in children without meningitis is an extremely rare condition of the central nervous system, it is probably a devastating neurological condition. And it is difficult to diagnose immediately, as this condition is one of the treatable conditions of paraparesis. We concluded that early diagnosis and treatment is crucial; before a dangerous vascular insult of the spinal cord is established from rapid formation of the abscess and an expansion of the spinal cord within the limited intraspinal space, In this communication, We report a case in child treated successfully with surgical drainage, intravenous antibiotics and neurorehabilitation between 2016 and 2017 and discuss the result.
\end{abstract}

Keywords: Intramedullary spinal cord abscess; Dermal sinus; Myelotomy

\section{Introduction}

Intramedullary spinal cord abscesses are infrequently encountered in daily neurosurgical practice. Hart reported the earliest documented spinal cord abscess in 1830. Since then fewer than 120 cases have been reported in the literature [1-3]. They can difficultly be distinguished from neoplasms making an early diagnosis according to a clinical suspicion and the radiological findings are essential and then administering appropriate antibiotic therapy and surgical intervention are crucial to reduce the mortality and neurological sequelae. Several cases of ISCA were reported with the magnetic resonance imaging (MRI) findings in the previous literature, but to the best of our knowledge, only one case that was diagnosed as ISCA without any predisposing factor.

Dermal sinus tract is to be implicated as a source of this pathology in children. Spinal cord abscess may involve any part of the spinal cord but the thoraco-lumbar spine is the most frequent site; In children, limited laminectomy with myelotomy focused above the most bulbous segment of the spinal cord for drainage of the abscess and adequate antibiotics is the treatment of choice.

\section{Case Report}

\section{Clinical presentation}

In March 2016, a 10 year old boy referred to our OPD with history of back pain and rapid progressive leg weakness. No history of fever, chills or myalgia. On examination, the child was restless, her temperature was at 36.5. There was no anal cleft dimple, or any skin abnormality, meningeal irritation signs were negative. There was no history of infection, trauma, fever, or surgery of the spine. Upper limbs were normal, whereas the lower extremities were flail and hypotonic with observed no movement. The muscle strength was estimated at $5 / 5$ in the upper limbs; while the power in her legs graded as $1 / 5$, he had no tendon reflexes elicited. On blood testing at admission, the white blood cell count $(9100 / \mu \mathrm{L})$ was normal and the C-reactive protein level $(4.5 \mathrm{mg} / \mathrm{dL})$.

\section{Radiological findings}

The radiologist was diagnosed the lesion as intramedullary S.O.L as the imaging study demonstrated a swollen spinal cord with the intramedullary well circumscribed cystic lesion extending from C7 til D2, no dermal sinus tract and the dimple 


\section{Open Access Journal of Neurology \& Neurosurgery}

can also be noticed on the MRI and we decided the surgery for biopsy (Figure 1).

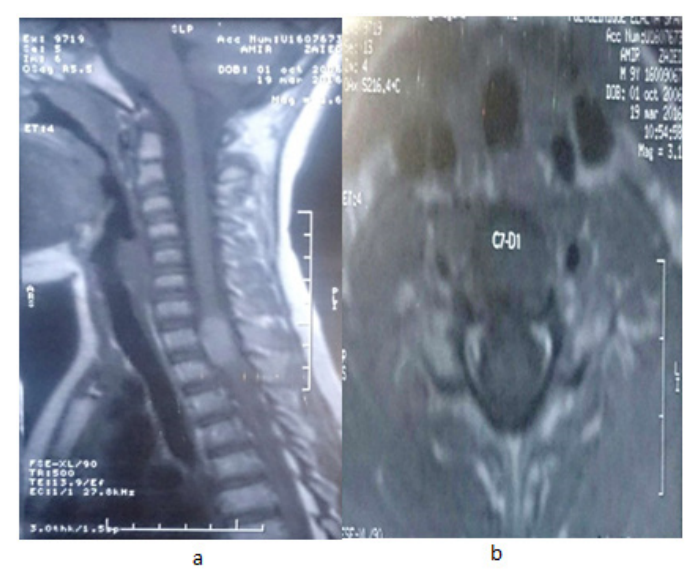

Figure 1: Cervico-dorsal spine preoperative MRI images T 2 sagittal (a) and T 1 axial (b) at C7-D1 level show intramedullary SOL.

\section{Intervention}

The child underwent an urgent surgical intervention within a few hours of her presentation C7til D 2 laminectomy was done, Using the microscope, the tense dura was opened above and below and reflected. amyelotomy was then made at C7,D1, D2level; a cystic lesion was opened from which a significant amount of viscous purulent fluid ran out a swab was taken for histopathology, Then, With gentle aspiration more purulent material was aspirated, irrigation with normal saline was then applied. The tension within the spinal cord relieved and the cord back to normal. The dura was then closed in a watertight fashion, as was the wound. The patient commenced intravenous antibiotics (Rocephine) for one week followed by oral antibiotic (Keflex) for another week.

\section{Pathology}

Evaluation of Gram-stain revealed no bacteria. Cultures of blood and the pus aspirate were negative.

\section{Postoperatively}

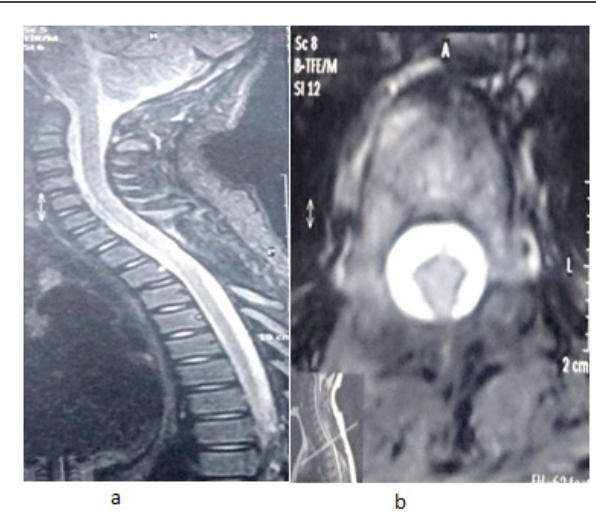

Figure 2: Cervico-dorsal spine preoperative MRI images $\mathrm{T}$ 2 sagittal (a) and T 2 axial (b) at D1-D2 level show complete removal of the abcess with complete cord regeneration.
The patient started to have some movements in his legs from day 5 . The leg strength continues to improve steadily. One month later, the child was able to move his legs spontaneously but still had visible residual weakness. Antibiotics ceased after 2 weeks and he was sent for neuro-rehabilitation. The postoperative MRI spine revealed a full resolution of the abscess and the regeneration of the cord was almost complete. The child displayed a significant neurological improvement on the regular assessment as an outpatient for nearly 11 months and now he is playing football (Figure 2).

\section{Discussion}

ISCA is a rare condition since the normal spinal cord tissue has remarkably high resistance to infection. The etiology of this condition is variable. from the mucosal surfaces extraspinal sites of infection [4]. Metastatic abscess infection $[5,6]$. Congenital midline defects $[4,5]$. Other causes are direct trauma or neurosurgical intervention [6]. Although 30\% of cases are microbiologically sterile, various organisms have been isolated, including Staphylococcus, Streptococcus pneumonia, Haemophilus, Proteus, Listeria, Actinomyces, Pseudomonas cepacia and Mycobacterium tuberculosis [7], In adults, blood route is the main source of ISCA. Congenital dermal sinus is implicated as the leading cause of ISCA in children.

The triad of ISCA is fever, pain and neurological deficits, but this does not occur in all patients [4]. Even with a marked reduction in the mortality and morbidity rate in the post antimicrobial era, this infection may result in a considerable damage to the spinal cord and the neurological outcome may remain critical. Still, early diagnosis and appropriate surgical intervention with administration of wide spectrum antibiotics is the main stay to prevent neurological disability and to improve the functional outcome. Magnetic resonance imaging with gadolinium contrast is the gold-standard of investigation, MRI is also helpful in demonstrating the co-existence of congenital anomalies .However, there has been only one report that has described the diagnostic value of DWI and ADC in ISCA $[8,9]$.

\section{Conclusion}

Suspicion of spinal cord abscess should be high in patients with dermal sinus and rapid progressive weakness in particular those who develop febrile illness. Entire spine MRI is essential in assessing all patients and for planned surgery. Before irreversible spinal cord damage can occur; timely surgical drainage through laminectomy and myelotomy with adequate antibiotics is considered as an effective model of treatment with good results in the conditions where dermal sinus is existed, it is still highly recommended to eradicate the sinus once it is found.

\section{References}

1. Dörflinger-Hejlek E, Kirsch EC, Reiter H, Opravil M, Kaim AH (2009) Diffusion-weighted MR imaging of intramedullary spinal cord abscess. AJNR Am J Neuroradiol 31(9): 1651-1652. 
2. Hart J (1830) Case of encysted abscess in the center of the spinal cord. Dublin Hospital Report 5: 522-524.

3. Kurita N, Sakurai Y, Taniguchi M, Terao T, Takahashi H, et al. (2009) Intramedullary spinal cord abscess treated with antibiotic therapycase report and review. Neurol Med Chir (Tokyo) 49(6): 262-268.

4. Bavdekar SB, Rao N, Kamat JR (1997) Intramedullary spinal cord abscess. Indian J Pediatr 64: 428-431.

5. Chan CT, Gold WL (1998) Intramedullary abscess of the spinal cord in the antibiotic era: clinical features, microbial etiologies, trends in pathogenesis, and outcomes. Clin Infect Dis 27(3): 619-626.
6. DiTullio MV (1977) Intramedullary spinal abscess: a case report with a review of 53 previously described cases. SurgNeurol 7(6): 351-354

7. Erashin Y (2003) Intramedullary abscess of the spinal cord. Childs Nerv Syst 19(10-11): 777.

8. Arzt PK (1944) Abscess within the spinal cord: review of the literature and report of three cases. Arch Neurol Psychiatry 51: 533-543.

9. Bartels RH, Gonera EG, Van der Spek JA, Thijssen HO, Mullaart RA, et al. (1995) Intramedullary spinal cord abscess. A case report. Spine 20: 1199-1204.

Your next submission with Juniper Publishers
will reach you the below assets
- Quality Editorial service
- Swift Peer Review
- Reprints availability
- E-prints Service
- Manuscript Podcast for convenient understanding
- Global attainment for your research
- Manuscript accessibility in different formats
( Pdf, E-pub, Full Text, Audio)
- Unceasing customer service
Track the below URL for one-step submission
https://juniperpublishers.com/online-submission.php

